\title{
BMJ Global Health How the concept of WHO-listed authorities will change international procurement policies for medicines
}

\author{
Cécile Macé, ${ }^{1}$ Lembit Rägo, ${ }^{2}$ Raffaella Ravinetto (D) ${ }^{3}$
}

\begin{abstract}
To cite: Macé C, Rägo L, Ravinetto R. How the concept of WHO-listed authorities will change international procurement policies for medicines. BMJ Global Health 2022;6:e008109. doi:10.1136/ bmjgh-2021-008109
\end{abstract}

Handling editor Seye Abimbola

Received 24 November 2021 Accepted 26 January 2022

Check for updates

(C) Author(s) (or their employer(s)) 2022. Re-use permitted under CC BY-NC. No commercial re-use. See rights and permissions. Published by BMJ.

1 Independent Consultant, Nantes, France

${ }^{2}$ Secretary-General, Council for International Organisations of Medical Sciences, Geneva, Switzerland

${ }^{3}$ Department of Public Health, Institute of Tropical Medicine Antwerp, Antwerp, Belgium

Correspondence to Dr Raffaella Ravinetto; rravinetto@itg.be
Well-functioning national pharmaceutical systems are essential to provide equitable access to quality-assured health products, and they are a powerful mean of promoting health equity ${ }^{1}$ and achieving universal health coverage. ${ }^{2}$ Unfortunately, quality-assured health products are far from being available to all. The WHO estimates a prevalence of poor-quality medicines ${ }^{4}$ of about $10 \%$ in low/middle-income countries (LMICs) ${ }^{5}$ at least partly due to the lack of stringent oversight by under-resourced national regulatory authorities (NRAs). ${ }^{6}$ Poor-quality medicines therefore particularly hit the most poor and disadvantaged populations. ${ }^{7}$

The quality assurance policies of the Global Fund, ${ }^{8}$ the United Nations Development Program, ${ }^{9}$ other UN agencies ${ }^{10}$ and most international organisations involved in funding and/or procuring health products rely on the approval (listing) by the WHO prequalification programme, ${ }^{11}$ and on the marketing authorisation of stringent regulatory authorities (SRAs). Other products can be eligible for procurement, but only after an additional assessment conducted according to WHO norms and standards. An SRA is an NRA with the resources and expertise needed for adequately carrying out the regulatory functions-among them, assessing data about medicines' quality, safety and efficacy; and conducting the necessary regulatory inspections, including clinical trial sites, and manufacturing sites of active ingredients and finished dosage forms. ${ }^{12}$ Major international purchasers consider that health products with a marketing authorisation issued by an SRA can be relied upon and do not need reassessment to be eligible for procurement, provided that the supplier can prove that the proposed product is essentially the same in all aspects (manufacturing site, specifications and so on) indicated in the SRA marketing authorisation. In addition,
Summary box

- The concept of stringent regulatory authorities (SRAs) is due to be replaced in the middle or longterm by the concept of 'WHO-listed authority' (WLA)

- The WHO started in 2016 a formal Globa Benchmarking for national regulatory authorities (NRAs), incorporating the concepts of 'maturity level' on a 1-4 scale, and of 'reliance'. Reaching a maturity level 3 is a step toward possible WLA designation.

- The major international purchasers of medicines currently rely on marketing authorisations issued by SRAs and on approval (listing) by WHO prequalification programme. We contend that the future WLAs should be equated to and trusted like SRA for the scope of designation.

- The time is also ripe for a reflection on whether and how procurement policies can incorporate the concept of 'maturity level', based on a thoughtful, stepwise approach accompanied by rigorous monitoring and evaluation. By doing so, the efforts of NRAs to reach maturity levels 3 and 4 would be fairly acknowledged; and there would be an incentive for other countries to invest in the development of their NRAs and to be listed as WLA.

national procurement centres/departments may also give preference in their tenders to health products that are pre-qualified by the WHO or registered by an SRA. The SRA classification was based until recently on affiliation to the International Council for Harmonisation of Technical Requirements for Pharmaceuticals for Human Use (ICH), which until its 2015 reform had only regulators from selected high-income regions as members (USA, European Union, Japan) and observers (Switzerland and Canada). ${ }^{13}$ Until 2017, a regulatory authority was classified as SRA if it was a member or an observer of ICH or was associated with an ICH member through a legally binding mutual recognition agreement (Australia, Iceland, Liechtenstein and Norway). In 2017, to take into account structural changes at ICH, the WHO adopted 
a new interim definition, specifying that SRAs are those NRAs that were members or observers of ICH or associated with an ICH member 'as before 23 October 2015' ${ }^{12}$

\section{FROM SRA TO WHO-LISTED AUTHORITY}

The concept of SRA linked to ICH structure was grounded in the availability of adequate human, financial and infrastructural resources, and of robust and transparent procedures, with the aim of achieving international recognition. However, it also corresponded to a pre-existing 'multiregional' harmonisation initiative, and to countries' income and industrialisation level. This may have led to misunderstandings and frustration, because of an inaccurate but possible perception that NRAs must just be located in the industrialised north for being considered stringent, irrespectively of their performance. But the concept of SRA will be replaced by the concept of 'WHO-listed authority' (WLA).

A benchmarking of regulatory systems was started by WHO in 1997 for vaccines, and in 2001 for medicines. As part of the WHO implicit mandate to support countries regulatory systems, and in response to the World Health Assembly Resolution 67.20 (2014) ${ }^{14}$ the use of a unified and improved WHO Global Benchmarking Tool (GBT) for medicines and vaccines began in 2016. It implies a structured and documented process, by which the NRA is assessed according to a set of indicators established for each regulatory function. The most recent version at the time of writing is the one published in $2021 .^{15} \mathrm{It}$ lists nine regulatory functions (ie, National Regulatory System, Registration and Marketing Authorisation, Vigilance, Market Surveillance and Control, Licensing Establishments, Regulatory Inspection, Laboratory Testing, Clinical Trials Oversight, NRA Lot Release). ${ }^{16}$ The GBT incorporates the concept of 'maturity level' (as adopted from ISO 9004) ${ }^{15}$ : at level 1 , only some elements of the regulatory system exist; at level 2, an evolving regulatory system partially performs essential regulatory functions; level 3 represents the minimum target, that is, a stable, well-functioning and integrated regulatory system; and level 4 represents a regulatory system operating at advanced level of performance and continuous improvement. ${ }^{17}$

The choice to use the GBT to assess its NRA is based on a voluntary decision of a Member State. It can be selfapplied or applied by independent experts appointed by the WHO. In the latter case, the NRA is transparently and consistently classified based on the assessment's result. Through this exercise, the NRA can identify and address gaps, with the goal of reaching at least maturity level $3 .^{15}$ Importantly, an NRA can reach a (high) maturity level in certain functions, while using explicit 'reliance' mechanisms for other ones. For example, an NRA that lacks the expertise and resources needed to assess applications for new chemical entities, or for vaccines, may use a transparent reliance procedure, for recognising the relevant regulatory decisions of the NRA that has the respective expertise and resources, or the listing from WHO prequalification. The reliance mechanism or procedure, which should include a list of 'recognised' NRAs, empowers less mature regulators to reach a given maturity level by strengthening their priority functions (eg, the assessment of generic medicines), while using reliance for more sophisticated functions. ${ }^{18}$ Its use is based on the assumption that the country has adequate legal provisions and instruments to facilitate and enable implementation of reliance.

The GBT replaces any previous WHO tools, representing the first truly 'global' tool for benchmarking regulatory systems. ${ }^{15}$ In 2020, the WHO Expert Committee on Specifications for Pharmaceutical Preparations formally adopted the definition of a 'WLA', that is, 'a regulatory authority or a regional regulatory system which has been documented to comply with all the relevant indicators and requirements specified by WHO for the requested scope of listing based on an established benchmarking and performance evaluation process'. Importantly, WLA must be capable of performing themselves all functions within its scope of designation. The Committee also asked the WHO Secretariat to prepare a situation analysis and propose ways to replace references to SRAs by WLAs in guidance texts. A roadmap for developing operational guidance, including performance evaluation process has been established. The draft 'WLA operational guidance for evaluating and publicly designating regulatory authorities as WHO-listed authorities' describes the framework's operationalisation and indicates that the ultimate responsibility and decision for use of the WLA list resides with the users and depends on the specific context of its intended use. ${ }^{19}$

Reaching a maturity level 3 is not synonymous to being a future WLA (starting in 2022), but rather an entry point that leads to further evaluation, in view of a possible WLA designation. Getting WLA designation will require consistently meeting a set of indicatorsincluding selected maturity level 4 indicators, equivalent to the requirements of the WHO prequalification programme. At the time of writing, and looking at the interim list of NRAs posted on WHO website, ${ }^{20}$ a few NRAs from LMICs have attained maturity level 3, that is, Ghana and Tanzania for medicines and vaccines, as importing countries; and India, Indonesia, Vietnam, Serbia and Thailand for vaccines only, as producing countries. ${ }^{21}$ Tanzania and Ghana achieved this result respectively in 2018 and 2020, thanks to significant investments supported by a strong political commitment. Even if maturity level 3 does not imply becoming a WLA, it represents an important milestone in ensuring that appropriate structures and resources are available to assure adequate regulatory oversight. The WLA designation will further indicate countries whose regulatory systems in specified functions can be consistently relied on, based on an objective external assessment (not in place for SRAs) and accompanied by clear specifications for the scope of designation (not in place for the 'blanket' classification of SRA). 


\section{IMPLICATIONS FOR INTERNATIONAL PROCUREMENT?}

We contended earlier that it is ethically imperative not to compromise on medicines quality assurance. This may imply, when making concrete purchase decisions, choosing medicines with a higher purchase 'cost'. However, these relatively more expensive medicines will have a better overall 'value', given that non-quality-assured medicines may fail to cure and so impose higher costs on the health system. Any exceptions should be explicitly motivated by exceptional and temporary circumstances, and based on a meaningful risk-benefit assessment. ${ }^{22}$ For instance, the WHO Expert Review Panel is an independent advisory body of technical experts which assesses the potential quality risks of pharmaceutical products that do not yet meet all stringent quality requirements, when there are no alternatives, based on transparent science-based criteria. ${ }^{23}$ The current reliance of major international purchasers on marketing authorisations issued by SRAs and on the WHO prequalification listing is fully justified by the need to avoid quality problems in procurement and related, preventable harm. But with the introduction of the concepts of regulatory maturity and WLA, the time is ripe for a reflection on how these policies can be updated by incorporating these concepts to orient procurement decisions. First, WLA will be regulatory authorities with a high performance, able to comply with all the relevant indicators and requirements specified by WHO for the requested scope of listing, and capable of performing themselves (with no use of the reliance mechanism) the functions within scope of designation. As such, when WLAs will be formally listed, they will be equivalent to SRA and WHO prequalification in terms of performance, and they should be equated to SRAs for procurement purpose and within the scope of designation.

Second, if a maturity level L3 indicates a stable, wellfunctioning and integrated regulatory system, able to issue marketing authorisations based on a thorough assessment of the manufacturing site and product dossier (including by means of explicit reliance mechanisms as needed), it would seem reasonable for international purchasers to consider reliance on marketing authorisations issued by NRAs that reached maturity level 3 as confirmed by the WHO. Given that a maturity level 3 is not equivalent to being a WLA or WHO prequalification, and having in mind the overarching principle of risk-management, ${ }^{22}$ this should be done step-by-step. For instance, procurement policies could be adapted starting with lower-risk products, such as generic solid dosage forms that do not need in vivo bioequivalence studies as per the WHO 'biowaiver list' (ie, a proposal to waive in vivo bioequivalence requirements for WHO Model List of Essential Medicines immediate-release, solid oral dosage forms ${ }^{24}$ ). In a first phase, these could be considered as eligible for purchase if registered by an NRA with maturity level 3 . They could be followed, after positive experience, by those requiring in vivo bioequivalence studies; and the policy could gradually evolve to more complicated, higher-risk products, for example, injectable products, provided that they are in the scope of designation.

In conclusion, WLAs will be equivalent to SRA in terms of performance, so they should be trusted like SRA. Furthermore, the WLA classification will bring more transparency and evidence-based decisions than current policies based on SRA; and it will open the possibility to expand the recognised pool of regulatory agencies with full capacity and performance by specific functions.

Conversely, incorporating the concept of maturity level 3 in the procurement policies of global purchasers will require a stepwise approach, with ongoing monitoring and evaluation. Such policies would fairly acknowledge the efforts of NRAs to reach maturity levels 3 and 4; and could create an incentive for other LMICs to invest in the development of their NRAs, to maximise the protection of individual and public health.

\section{Twitter Raffaella Ravinetto @RRavinetto}

Contributors The initial draft version of this manuscript was written by $\mathrm{CM}$ and RR. LR provided substantial inputs. All authors approved the submitted version. RR is the guarantor of this analysis and the corresponding author.

Funding RR is funded by the Belgian Directorate-General for Development Cooperation (DGD), through the Framework Agreement 5, 2022-2026 with the Institute of Tropical Medicine, Antwerp.

Competing interests None declared.

\section{Patient consent for publication Not applicable.}

Ethics approval This work does not involve human participants, human data nor human samples.

Provenance and peer review Not commissioned; externally peer reviewed. Data availability statement There are no data in this work.

Open access This is an open access article distributed in accordance with the Creative Commons Attribution Non Commercial (CC BY-NC 4.0) license, which permits others to distribute, remix, adapt, build upon this work non-commercially, and license their derivative works on different terms, provided the original work is properly cited, appropriate credit is given, any changes made indicated, and the use is non-commercial. See: http://creativecommons.org/licenses/by-nc/4.0/.

\section{ORCID iD}

Raffaella Ravinetto http://orcid.org/0000-0001-7765-2443

\section{REFERENCES}

1 Bigdeli M, Peters DH, Wagner AK, eds. Medicines in health systems: advancing access, affordability and appropriate use. AHPSR/WHO, 2014.

2 Ozawa S, Higgins CR, Yemeke TT, et al. Importance of medicine quality in achieving universal health coverage. PLoS One 2021;15:e0232966.

3 Orubu ESF, Ching C, Zaman MH, et al. Tackling the blind spot of poor-quality medicines in universal health coverage. J Pharm Policy Pract 2020;13:40.

4 World Health Organization. Essential medicines and health products. substandard and falsified (SF) medical products. definitions of substandard and falsified (SF) medical products. Geneva: World Health organization, 2017. Available: https://www.who.int/medicines/ regulation/ssffc/A70_23-en1.pdf?ua=1 [Accessed 25 May 2020].

5 World Health Organization. Global surveillance and monitoring system for substandard and falsified medical products. Geneva: World Health Organization, 2017.

6 Newton PN, Bond KC, Oxford Statement signatories. Global access to quality-assured medical products: the Oxford statement and call to action. Lancet Glob Health 2019;7:e1609-11.

7 Ravinetto R, Vandenbergh D, Macé C, et al. Fighting poor-quality medicines in low- and middle-income countries: the importance of advocacy and pedagogy. J Pharm Policy Pract 2016;9:36. 
8 Global Fund Quality Assurance Policy for Pharmaceutical Products. Medicines - Sourcing \& Management of Health Products - The Global Fund to Fight AIDS, Tuberculosis and Malaria, 2021.

$9 \mathrm{WHO}$. WHO quality assurance policy for the procurement of essential medicines and other health products UNDP quality assurance policy and plan | UNDP global fund implementation guidance manual (undphealthimplementation.org), 2021. Available: https://www.who.int/publications/i/item/9789240023789 [Accessed 30 Aug 2021].

10 Ensuring quality. The quality of goods and services that UNICEF procures for children is key to delivering results for every child: ensuring quality | UNICEF supply division, 2021. Available: https:// www.unicef.org/supply/ensuring-quality [Accessed 16 Nov 2021].

11 WHO. WHO - Prequalification of Medical Products (IVDs, Medicines, Vaccines and Immunization Devices, Vector Control) | WHO Prequalification of Medical Products (IVDs, Medicines, Vaccines and Immunization Devices, Vector Control), 2021. Available: https:// extranet.who.int/pqweb/ [Accessed 16 Nov 2021].

12 WHO. Fifty-first report of the WHO Expert Committee on specifications for pharmaceutical preparations. Geneva: World Health Organization; 2017 (WHO technical report series ; no. 1003). Licence: CC BY-NC-SA 3.0 IGO. Available: https://www. who.int/medicines/areas/quality_safety/quality_assurance/expert committee/WHO_TRS_1003_full-version.pdf?ua=1 [Accessed 16 Nov 2001].

$13 \mathrm{ICH}$. International Council for harmonisation of technical requirements for pharmaceuticals for human use (ICH). Available: https://www.ich.org/page/mission [Accessed 19 Nov 2021].

14 67th World Health Assembly, 2020. Resolution "Regulatory system strengthening for medical products". Agenda item 15.6, 2014. Available: https://apps.who.int/gb/ebwha/pdf_files/WHA67/A67 R20-en.pdf [Accessed 16 Nov 2021].

15 WHO. Global benchmarking tool (GBT) for evaluation of national regulatory systems of medical products, revision VI. Geneva: World Health Organization, 2021.

16 Guzman J, O'Connell E, Kikule K, et al. The who global benchmarking tool: a game changer for strengthening national regulatory capacity. BMJ Glob Health 2020;5:e003181.

17 Khadem Broojerdi A, Baran Sillo H, Ostad Ali Dehaghi R, et al. The world Health organization global benchmarking tool an instrument to strengthen medical products regulation and promote universal health coverage. Front Med 2020;7:457.

18 WHO. Expert Committee on specifications for pharmaceutical preparations: Fifty-fifth report. Geneva: World Health Organization; (WHO Technical Report Series, No. 1033), 2021.

19 World Health Organization (WHO). WLA operational guidance evaluating and publicly designating regulatory authorities as WHOlisted authorities. draft working documents for comments. WHOListed authority (WLA), 2021. Available: https://cdn.who.int/media/ docs/default-source/medicines/regulatory-systems/wla_operationalguide_finaldraft_rev-1.pdf?sfvrsn=241f19d6_5 [Accessed 16 Nov 2021].

20 World Health Organization. A framework for evaluating and publicly designating regulatory authorities as WLA. WHO-Listed authority (WLA). Available: https://wwwwhoint/initiatives/who-listed-authorityreg-authorities [Accessed 16 Nov 2021].

21 List of national regulatory authorities (NRAS) operating at maturity level 3 (ML3) and maturity level 4 (ML4) (as benchmarked against who global benchmarking tool (GBT). Available: https://www.who. int/initiatives/who-listed-authority-reg-authorities/MLA4 [Accessed 05 Oct 2021].

22 Ravinetto R, Pinxten W, Rägo L. Quality of medicines in resourcelimited settings: need for ethical guidance. Global Bioethics 2018;29:81-94

23 Expert review panel. Expert Review Panel | WHO - Prequalification of Medical Products (IVDs, Medicines, Vaccines and Immunization Devices, Vector Control), 2022. Available: https://extranet.who.int/ pqweb/medicines/expert-review-panel [Accessed 11 Jan 2021].

24 World Health Organization (WHO). "Biowaiver List": proposal to waive in vivo bioequivalence requirements for WHO Model List of Essential Medicines immediate-release, solid oral dosage forms. Annex 12 to the fifty-fourth report of the WHO Expert Committee on Specifications for Pharmaceutical Preparations. WHO Technical Report Series, No. 1025, 2020. Available: https://cdn.who.int/ media/docs/default-source/medicines/who-technical-report-serieswho-expert-committee-on-specifications-for-pharmaceuticalpreparations/trs1025-annex12.pdf?sfvrsn=f875ed4b_2 [Accessed 11 Jan 2022]. 